\title{
Correction to: Defining the Abatement Cost in Presence of Learning-by-Doing: Application to the Fuel Cell Electric Vehicle
}

\author{
Anna Creti $^{1}$ - Alena Kotelnikova ${ }^{2}$ - Guy Meunier ${ }^{2,3}$. \\ Jean-Pierre Ponssard ${ }^{2,4}$
}

Published online: 6 December 2017

(C) Springer Science+Business Media B.V. 2017

\section{Correction to: Environ Resource Econ https://doi.org/10.1007/s10640-017-0183-y}

The correct affiliation for Anna Creti is: Université Paris-Dauphine, PSL Research University, LEDa, CGEMP, 75016 Paris, France

The following acknowledgment was missing from the original article:

The authors would like to thank Michel Moreaux, Adrien Vogt-Schilb and Fabien Prieur for their comments, and participants to workshops or conferences at IPAG, Paris, FAERE, Toulouse, CESifo, Munich. Financial support from the Chair Energy et Prosperity at Fondation du Risque is gratefully acknowledged.

The original article can be found online at https://doi.org/10.1007/s10640-017-0183-y.

$\triangle$ Guy Meunier

guy.meunier@ivry.inra.fr

1 LEDa, CGEMP, Université Paris-Dauphine, PSL Research University, 75016 Paris, France

2 CREST, Ecole Polytechnique, Université Paris-Saclay, route de Saclay, 91128 Saclay, France

3 INRA-UR1303 ALISS, 65 boulevard de Brandebourg, 94200 Ivry-Sur-Seine, France

4 CREST, CNRS, Ecole Polytechnique, Université Paris-Saclay, route de Saclay, 91128 Saclay, France 